\title{
Randomized, Double-Blind, Placebo-Controlled Study of Encenicline, an $\alpha 7$ Nicotinic Acetylcholine Receptor Agonist, as a Treatment for Cognitive Impairment in Schizophrenia
}

\author{
Richard SE Keefe', Herbert A Meltzer², Nancy Dgetluck ${ }^{3}$, Maria Gawryl ${ }^{3,4}$, Gerhard Koenig ${ }^{3}$, Hans J Moebius ${ }^{3}$, \\ Ilise Lombardo ${ }^{3,5}$ and Dana C Hilt*,3 \\ 'Department of Psychiatry and Behavioral Sciences, Duke University Medical Center, Durham, NC, USA; ${ }^{2}$ Department of Psychiatry and Behavioral \\ Sciences Psychiatry, Northwestern University, Feinberg School of Medicine, USA; ${ }^{3}$ FORUM Pharmaceuticals Inc., Waltham, MA, USA
}

\begin{abstract}
Encenicline is a novel, selective $\alpha 7$ nicotinic acetylcholine receptor agonist in development for treating cognitive impairment in schizophrenia and Alzheimer's disease. A phase 2, double-blind, randomized, placebo-controlled, parallel-design, multinational study was conducted. Patients with schizophrenia on chronic stable atypical antipsychotics were randomized to encenicline 0.27 or $0.9 \mathrm{mg}$ once daily or placebo for 12 weeks. The primary efficacy end point was the Overall Cognition Index (OCl) score from the CogState computerized battery. Secondary end points include MATRICS Consensus Cognitive Battery (MCCB) (in US patients), the Schizophrenia Cognition Rating Scale (SCoRS) total score, SCoRS global rating, and Positive and Negative Syndrome Scale (PANSS) total and subscale and cognition factor scores. Of 319 randomized patients, 317 were included in the safety population, and 307 were included in the intent-totreat population. Notable trends in improvement were demonstrated across all cognition scales. For the OCl score, the LS mean difference for encenicline $0.27 \mathrm{mg}$ vs placebo was significant (Cohen's $d=0.257 ; P=0.034$ ). Mean SCoRS total scores decreased showing improvement in function over time, and the difference was significant for encenicline $0.9 \mathrm{mg}$ vs placebo $(P=0.0 \mathrm{II})$. Furthermore, the difference between encenicline $0.9 \mathrm{mg}$ and placebo was significant for the PANSS Cognition Impairment Domain $(P=0.0098$, Cohen's $d=0.40)$ and for the PANSS Negative scale $(P=0.028$, Cohen's $d=0.33)$. Treatment-emergent adverse events were reported at similar frequencies across all treatment groups (39.0\% with placebo, $23.4 \%$ with encenicline $0.27 \mathrm{mg}$, and $33.3 \%$ with encenicline $0.9 \mathrm{mg}$ ). Overall, encenicline was generally well tolerated and demonstrated clinically meaningul improvements in cognition and function in patients with schizophrenia.

Neuropsychopharmacology (20 I5) 40, 3053-3060; doi: I 0.I038/npp.20 I5. I76; published online I5 July 20 I5
\end{abstract}

\section{INTRODUCTION}

Nearly all patients with schizophrenia demonstrate cognitive impairment that is evident across multiple domains, including attention/vigilance, verbal learning and memory, executive functioning, verbal fluency, and speed of processing (Harvey and Keefe, 1997; Heinrichs and Zakzanis, 1998). Cognitive impairment is often apparent before or at the time of a first psychotic break (Saykin et al, 1994; Bilder et al, 2000) and persistent throughout all stages of illness. The magnitude of cognitive impairment is on average 2 SDs below the healthy control mean (Saykin et al, 1991; Keefe et al, 2011), and the severity of impairment is more predictive of functional outcomes than positive and negative symptoms (Harvey et al, 1997). Cognitive impairment in this

*Correspondence: Dr DC Hilt, FORUM Pharmaceuticals Inc., 225 Second Avenue, Waltham, MA 0245I, USA, Tel: + I 6172254250 , Fax: + | 617225 4267, E-mail: dhilt@forumpharma.com

${ }^{4}$ Current address: Tetraphase Pharmaceuticals, Watertown, MA, USA. ${ }^{5}$ Current address: Axovant Sciences Inc., New York, NY, USA.

Received I 8 March 2015; revised I4 April 2015; accepted 3 June 2015; accepted article preview online 19 June 2015 patient population has been shown to be consistently associated with unemployment, limited social functioning, and poor quality of life, and is widely accepted as the chief determinant of long-term disability (Green et al, 2004; Mohamed et al, 2008).

There is a clear need for pharmacological agents that target cognitive impairment in schizophrenia for which there are currently no approved medications. To meet this need, novel medications will need to be assessed for effect in two areas: improvement in cognition using a validated measure that covers the broad spectrum of cognitive domains as well as the demonstration of improvement in clinically relevant functioning. Thus, the improvement of cognitive impairment, because of its impact on patient functioning, is increasingly recognized as an essential goal to improve patient care and represents a significant unmet medical need.

The $\alpha 7$ nicotinic acetylcholine receptors ( $\alpha 7$ receptors) have been shown to play an important role in cognition in both animals and humans and have potential therapeutic applications in cognitive impairment in schizophrenia as well as Alzheimer's disease. Activation of the $\alpha 7$ receptors increases cholinergic neurotransmission and the release of 
glutamate (Glu) and dopamine (DA) exerts procognitive effects in rats (Picciotto et al, 1998; Pichat et al, 2007; Barik and Wonnacott, 2009; Huang et al, 2014). Encenicline is an agonist exhibiting priming behavior at the $\alpha 7$ receptor by potentiating the response to the natural agonist acetylcholine (ACh) (Prickaerts et al, 2012). Encenicline may work as a neuromodulator, with its impact on cognition mediated in part by modulating multiple neurotransmitter systems including DA, ACh, and Glu in the prefrontal cortex and other brain regions (Huang et al, 2014). In a prior study in patients with schizophrenia, encenicline demonstrated normalizing effects on evoked response potentials (Mismatch Negativity, P300) that have been shown to be consistently abnormal in patients with schizophrenia (Preskorn et al, 2014). Procognitive effects of encenicline were observed in normal subjects (Barbier et al, 2015). The purpose of this phase 2 study was to evaluate the potential procognitive and functional effects of encenicline in patients with schizophrenia or schizoaffective disorder treated with stable doses of antipsychotic medication.

\section{MATERIALS AND METHODS}

The study protocol, protocol amendments, and informed consent forms were reviewed and approved by independent institutional review boards/ethics committees. All participants provided written informed consent before screening.

\section{Study Design}

This was a 12-week, double-blind, randomized, placebocontrolled, parallel-design, multinational study. Screening evaluations included physical examination, vital signs, 12-lead electrocardiogram (ECG), and clinical laboratory tests. Following a screening visit, a 14-day single-blind placebo run in was completed to assess patient compliance, vital signs, and acclimate the patients to cognitive testing procedures. Eligible patients were subsequently randomly allocated $1: 1: 1$ to encenicline 0.27 or $0.9 \mathrm{mg}$ (equivalent to 0.3 and $1.0 \mathrm{mg}$ encenicline hydrochloride, respectively) or placebo once daily. Study visits occurred on days 7, 14, 28, 44 (for US sites only to obtain the MCCB), 56, 77, and 84 ( \pm 2 days). A follow-up telephone assessment was performed on day 91 to elicit information on adverse events.

\section{Patient Selection}

Male or female patients aged 18-55 years inclusive residing in a stable living situation were eligible if they had a diagnosis of schizophrenia or schizoaffective disorder of $\geq 3$-year duration utilizing the Structured Clinical Interview: Diagnostic and Statistical Manual of Mental Disorders, Fourth Edition, Text Revision (SCID-I for DSM-IV-TR Disorders-Axis I). Patients were required to have a nonacute illness, have an acceptable general health status, and be treated with a second-generation antipsychotic drug (excluding clozapine) at a stable dose for $\geq 4$ weeks and must have been on that drug and clinically stable for $\geq 8$ weeks before screening. Patients also were required to have moderate schizophrenia clinical symptom burden as defined as (1) no more than 'moderate' rating for positive symptoms (hallucinations and delusions) and a Brief Psychiatric Rating
Scale (BPRS; Overall and Gorham, 1962) Hallucinatory Behavior or Unusual Thought Content item score $\leq 4$; (2) no more than 'moderate' severity rating for formal thought disorder; BPRS Conceptual Disorganization item score $\leq 4$; (3) minimal level of extrapyramidal symptoms (EPS); Simpson-Angus Scale (SAS; Simpson and Angus, 1970) total score $\leq 6$; and (4) minimal level of depression; Calgary Depression Scale for Schizophrenia (CDSS) (Addington et al, 1990) total score $\leq 10$.

Patients were excluded with a history of hospitalization within 4 weeks or psychiatric hospitalization within 3 months of screening, treatment with more than one antipsychotic drug, or chronic treatment with anticholinergic agents. Patients were also excluded for use of any antidepressant, except for those on stable dose of a selective serotonin reuptake inhibitor for $\geq 3$ months before screening.

\section{Study Procedures}

The primary efficacy end point was the CogState Overall Cognition Index (OCI) score based on seven computerized tasks and two 'paper and pencil' tasks from the Neuropsychological Test Battery (NTB) (Trails 2 and 4) (Maruff et al, 2009). The CogState tasks included the International Shopping List Task (ISLT), Groton Maze Learning Test (GMLT), Detection (DET), Identification (IDN), One Card Learning (OCL), One-Back (ONB), and Social-Emotional Cognition Task (SECT). These cognitive performance tasks were completed at baseline, and on days 14, 28, 56, and 77 .

A secondary cognitive end point was the MATRICS Consensus Cognitive Battery (MCCB). The MCCB assesses cognitive change in patients with schizophrenia (Kern et al, 2008; Nuechterlein et al, 2008) and evaluates seven cognitive domains: speed of processing, attention/vigilance, working memory, verbal learning, visual learning, reasoning and problem solving, and social cognition. The MCCB was completed only by patients enrolled in the United States $(n=154)$ at baseline and on days 44 and 84 because of the lack of validated translations for the ex-US countries at the time this study was initiated. The change in the MCCB overall composite $T$-score (weighted sum of the 7 domain scores) and individual domain scores were assessed.

Additional secondary end points included the Schizophrenia Cognition Rating Scale (SCoRS) total score (Keefe et al, 2006), a 20-item rating scale of daily functioning related to cognitive impairment (Keefe et al, 2015). The SCoRS was administered at baseline and on days 28,56 , and 77 . The SCoRS rater integrated information from separate patient and informant interviews to generate a total score.

The Positive and Negative Syndrome Scale (PANSS; Kay et al, 1987) was administered at baseline, and on days 28,56 , and 77. Although the PANSS Negative Subscale was prespecified as a secondary end point, the PANSS Cognitive Impairment Domain was also evaluated in a post hoc analysis (Mohs et al, 2004).

Treatment-emergent adverse events (TEAEs), laboratory evaluations (hematology, blood chemistry, and urinalysis), physical examination, vital signs (blood pressure, pulse rate, temperature, respiratory rate), and 12-lead ECG were assessed at regular intervals throughout the study. Suicidal ideation was evaluated using the Columbia-Suicide Severity Rating Scale (C-SSRS; Posner et al, 2007), EPS were evaluated 
using the SAS, and prior and concomitant medications including antipsychotic medications were recorded.

\section{Statistical Analysis}

Sample size was based on the number of patients necessary to detect an effect size of 0.4 as being statistically significant at the $P<0.05$ criterion and providing $80 \%$ power and was calculated to require a total of 234 patients or 78 patients per group per pairwise comparison. As the analysis was conducted only to determine whether encenicline was better than placebo, and a result suggesting that it was worse would not be different than acceptance of the null hypothesis, statistical tests of efficacy in this phase 2 study were one tailed (Cohen, 1977). In order to reach the goal of 234 evaluable patients, $\sim 376$ patients were to be screened for an estimated randomization of 282 patients or 94 patients per group.

The primary efficacy end point was the computerized CogState OCI with the paper-based trails 2 and 4 . The pairwise comparison of each dose of encenicline and placebo was tested at the significance level of 0.05 (one sided) without any adjustment for multiple comparisons. The primary efficacy analysis was performed in the intent-to-treat (ITT) population, defined as any randomized patient who received drug and had at least one postbaseline efficacy assessment, using a linear mixed model (LMM) with the OCI score as the outcome that included treatment, assessment, and an interaction of treatment by assessment as factors; baseline OCI score as a covariate, and patient as a random effect. The least squares (LS) mean differences between each encenicline treatment group and placebo, 95\% confidence intervals (CIs), and $P$-values were calculated from pairwise comparisons. An exploratory post hoc analysis of the primary efficacy end point excluding the trails 2 and 4 was also performed to assess any potential confounding learning effect of the paperbased tests.
Secondary efficacy end points included the change in the MCCB overall composite $T$-score from baseline to day 84, the difference in change from baseline on the SCoRS Interviewer total score, and the PANSS total score, including the positive, negative, and general psychopathology subscale scores to day 77 . These scores were analyzed using LMM with fixed factors of baseline, treatment, protocol-specified visit, and interaction of treatment and visit. Baseline measures were treated as a covariate, and patient was treated as the random factor. The LS mean difference, SE, and 95\% CIs were estimated separately for each visit. A post hoc analysis of the change from baseline in the MCCB was also performed using similar methods, utilizing the last observation carried forward (LOCF), and including data from patients who terminated early and completed the assessments at an early-termination visit. An additional analysis of the cognition end points was performed with a stepwise model that included age, smoking status, disease duration, continent, antipsychotic, and baseline score as covariates.

EVP-6124-009 was registered at Clinicaltrials.gov (NCT00968851).

\section{RESULTS}

A total of 319 patients were randomized to treatment, but one patient was randomized to encenicline $0.9 \mathrm{mg}$ and placebo groups at two different study centers and was excluded from all further analyses. The remaining 317 patients were included in the safety population, and 307 patients meeting the criteria were included in the ITT population (Figure 1). The demographic and clinical characteristics were comparable between treatment groups at baseline (Table 1). Data on methods and results for plasma encenicline concentrations are included as Supplementary Data.

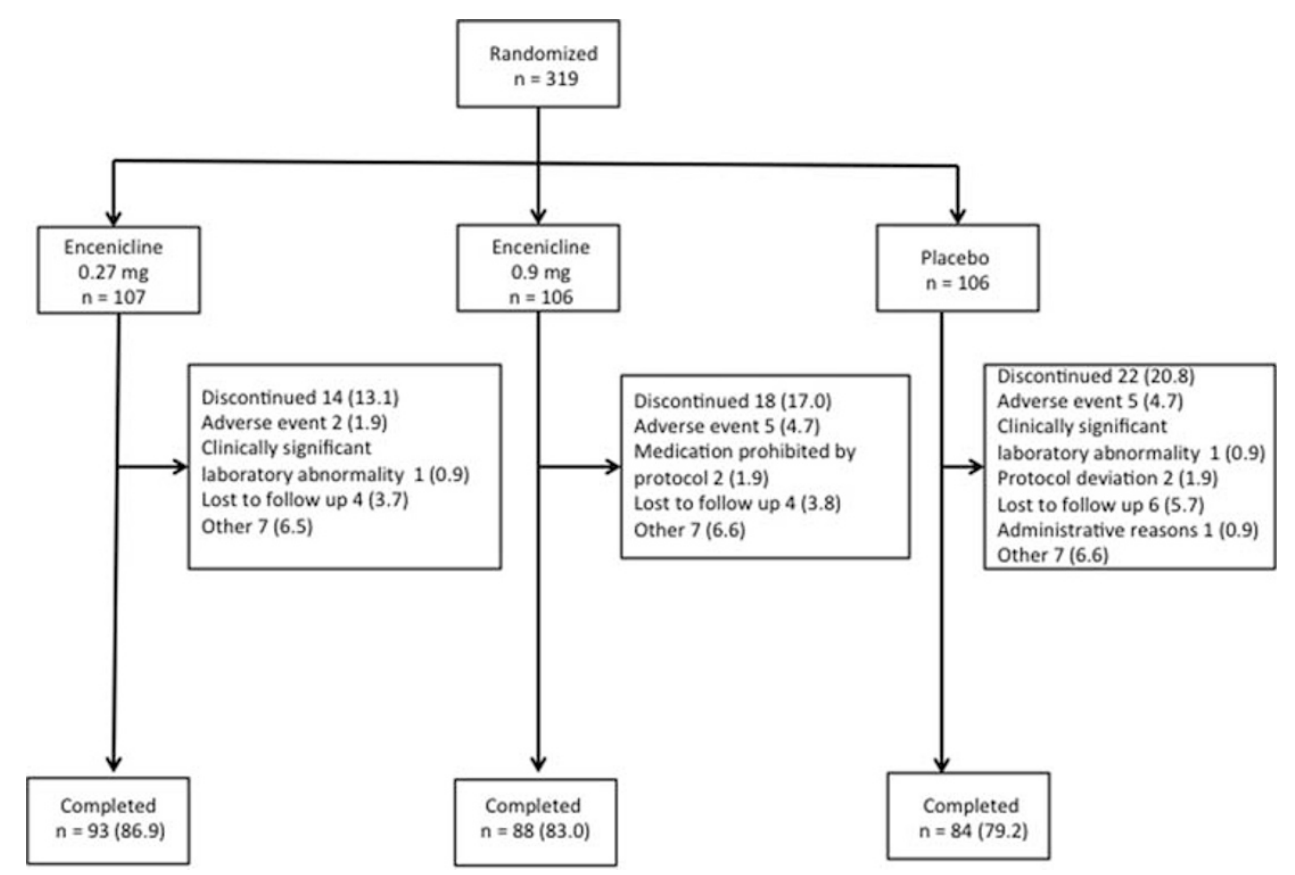

Figure I Patient disposition chart. 
Table I Patient Demographics

\begin{tabular}{|c|c|c|c|}
\hline & $\begin{array}{c}\text { Encenicline } \\
0.27 \mathrm{mg} \\
(n=107)\end{array}$ & $\begin{array}{c}\text { Encenicline } \\
0.9 \mathrm{mg} \\
(n=105)\end{array}$ & $\begin{array}{r}\text { Placebo } \\
(n=105)\end{array}$ \\
\hline Male/female, $n$ & $70: 37$ & $75: 30$ & $70: 35$ \\
\hline Mean (SD) age, years & 39.1 (9.7) & $37.3(10.5)$ & $39.2(9.9)$ \\
\hline Range, years & $21-55$ & | $8-55$ & $20-54$ \\
\hline Number $(\%)>30$ years & $80(74.8)$ & $72(68.6)$ & $79(75.2)$ \\
\hline Mean (SD) BMl, kg/m² & $27.0(4.2)$ & $27.7(4.3)$ & $28.1(4.4)$ \\
\hline \multicolumn{4}{|l|}{ Race, n (\%) } \\
\hline White & $72(67.3)$ & $64(61.0)$ & $72(68.6)$ \\
\hline Black or African American & $32(29.9)$ & $37(35.2)$ & 31 (29.5) \\
\hline Asian & $3(2.8)$ & I (I.0) & $2(1.9)$ \\
\hline Other & 0 & $3(2.9)$ & 0 \\
\hline $\begin{array}{l}\text { Smoking or tobacco use, } \\
n(\%)\end{array}$ & $55(51.4)$ & $57(54.3)$ & $66(62.9)$ \\
\hline Onset $\geq 10$ years, $n(\%)$ & $63(58.9)$ & $50(47.6)$ & $63(60.0)$ \\
\hline \multicolumn{4}{|l|}{ Current antipsychotic, n (\%) } \\
\hline Risperidone & $51(47.7)$ & $53(50.5)$ & $52(49.5)$ \\
\hline Quetiapine & $22(20.6)$ & $16(15.2)$ & $22(20.9)$ \\
\hline Olanzapine & $17(15.9)$ & $7(6.7)$ & II (I0.5) \\
\hline Aripiprazole & $10(9.3)$ & $8(7.6)$ & $12(12.4)$ \\
\hline Paliperidone & $4(3.7)$ & $13(12.4)$ & $4(3.8)$ \\
\hline Other & $3(2.8)$ & $8(7.6)$ & $4(3.8)$ \\
\hline
\end{tabular}

\section{Efficacy}

CogState overall cognition index. For the primary end point, CogState OCI score plus trails 2 and 4, the LS mean difference for encenicline $0.27 \mathrm{mg} v s$ placebo was 0.117 (Cohen's $d=0.257 ; P=0.034$ ) and for encenicline $0.9 \mathrm{mg} v s$ placebo was 0.042 (Cohen's $d=0.093 ; P=0.255$ ), indicating that encenicline $0.27 \mathrm{mg}$ was associated with significant improvements $v s$ placebo in general cognitive function (Figure 2b). For most tasks, these positive findings were more pronounced for encenicline than for placebo. Overall, the results did not significantly differ when evaluated by smoking status, age, disease duration, continent, concomitant antipsychotic, or baseline score (Supplementary Table 14.2.2.4).

The data in the main analysis, however, suggest that there were practice effects on the trail making tests (trails 2 and 4). A separate analysis was performed on the CogState OCI without the NTB trail 2 and 4 tasks to evaluate these practice effects on the overall score. The LS mean difference for encenicline $0.27 \mathrm{mg} v s$ placebo was 0.168 (Cohen's $d=0.336$; $P=0.009$ ) and for encenicline $0.9 \mathrm{mg} v s$ placebo was 0.057 (Cohen's $d=0.116 ; P=0.205$ ).

MATRICS consensus cognitive battery. At baseline, the mean MCCB overall composite $T$-score was similar across treatment groups (range: 26.6-31.0). All treatment groups showed a mean increase from baseline on days 44 and 84 .

In the analysis utilizing the LOCF, and including data from patients who terminated early and completed the assessments at an early-termination visit $(n=154)$, the mean change from baseline to day 84 was 2.9 and 3.3 for encenicline 0.27 and $0.9 \mathrm{mg}$, respectively, and 1.2 for placebo $(0.27 \mathrm{mg}: P=0.142$, Cohen's $d=0.17$ and $0.9 \mathrm{mg}: P=0.069$, Cohen's $d=0.28 v s$ placebo; Figure 2a). Furthermore, the mean change from baseline to day 84 was numerically greater for each encenicline group than placebo for the majority of domains comprising the MCCB, including speed of processing ( $0.9 \mathrm{mg}$ group), attention/vigilance $(0.9 \mathrm{mg}$ group), verbal learning (0.27 and $0.9 \mathrm{mg}$ group), and visual learning (0.27 mg group) (Supplementary Tables 14.2.2.4).

An additional post hoc analysis evaluated the effects of treatment on the PANSS Cognition Impairment Domain. LS mean change from baseline ranged from -0.3 to -0.4 with placebo, -0.4 to -0.95 with encenicline $0.27 \mathrm{mg}$, and -0.7 to -1.35 with encenicline $0.9 \mathrm{mg}$ at days 28,56 , and 77 (Figure 2c). The difference between encenicline $0.9 \mathrm{mg}$ and placebo was significant $(P=0.0098$, Cohen's $d=0.40)$, but the difference between encenicline $0.27 \mathrm{mg}$ and placebo was not $(P=0.186$, Cohen's $d=0.19)$.

Schizophrenia cognition rating scale. At baseline, the mean SCoRS total score was similar across treatment groups (range: 37.2-38.5). All treatment groups showed a mean decrease in the SCoRS total score on days 28,56 , and 77 , indicating improvement. The LS mean difference was significant for encenicline $0.9 \mathrm{mg} v s$ placebo $(P=0.011$, effect size: 0.36 ), but not for encenicline $0.27 \mathrm{mg} v s$ placebo $(P=0.970$, Cohen's $d=0.01$; Figure $3 \mathrm{a})$.

PANSS for schizophrenia. At baseline, the mean PANSS total score was similar across treatment groups consistent with moderate symptom severity (range: 63.3-66.4). A mean decrease in the PANSS total score from baseline was observed across all treatment arms, although changes were not significant.

At baseline, mean scores for the PANSS positive (14.3-5.0), negative (18.0-18.7), and general psychopathology (30.9-32.7) subscales were generally similar across treatment groups. All treatment groups showed a mean decrease in PANSS subscale scores from baseline on days 28 , 56, and 77. Changes from baseline for PANSS positive and general psychopathology subscale scores were minimal and did not statistically differ by treatment group. Overall, the lack of significant effects on the PANSS total score and PANSS positive and general psychopathology subscales suggest that treatment with encenicline did not exacerbate symptoms of schizophrenia.

In contrast, a prespecified analysis evaluated the effects of treatment on the PANSS negative subscale. Mean changes from baseline to day 77 were -0.71 for placebo, and -1.18 and -1.44 for encenicline 0.27 and $0.9 \mathrm{mg}$, respectively. A significant mean difference $(-0.7, P=0.028$, Cohen's $d=0.33$ ) was observed at day 77 between encenicline $0.9 \mathrm{mg}$ and placebo. The difference was not significant between encenicline $0.27 \mathrm{mg}$ and placebo at day 77 $(P=0.160$; Cohen's $d=0.20$; Figure $3 \mathrm{~b})$. 
a

$\underset{(\mathrm{n}=154)}{\operatorname{MCCB}(\mathrm{LOCF})}$

$0.27 \mathrm{mg}$ vs. placebo: $\mathrm{p}=0.142, \mathrm{ES}=0.17$

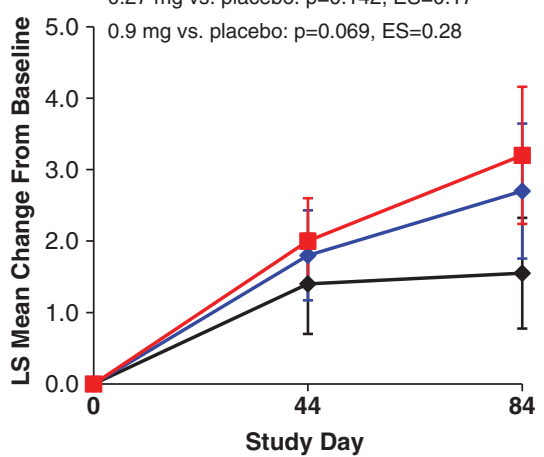

Encenicline $0.9 \mathrm{mg}$

b

$0.27 \mathrm{mg}$ vs. placebo: $\mathrm{p}=0.034, \mathrm{ES}=0.26$

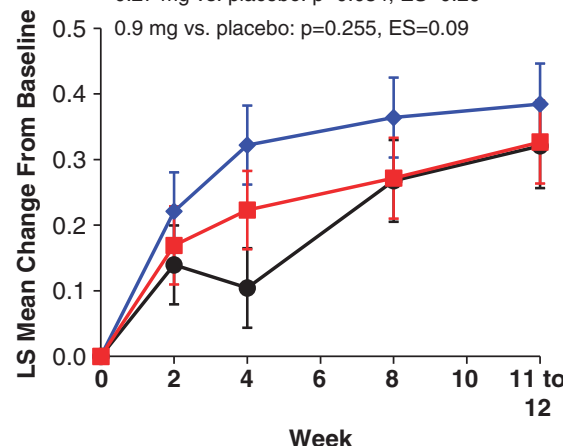

Placebo

C

PANSS "Cognitive Impairment" Domain

$0.27 \mathrm{mg}$ vs. placebo: $\mathrm{p}=0.816, E S=0.19$

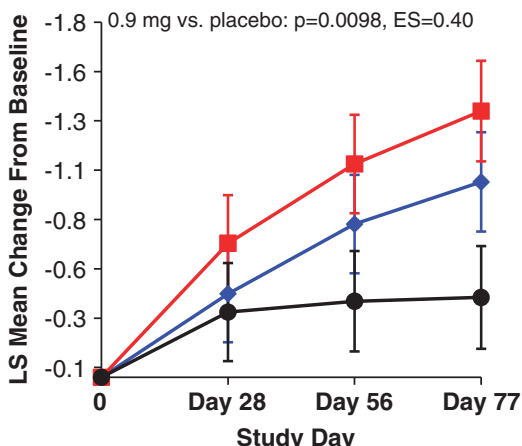

Figure 2 Composite figure of cognition scales. All data presented as mean \pm SEM. ES = Cohen's $d$ effect size. (a) MCCB: positive dose-dependent changes from baseline noted trending toward significance at the $0.9 \mathrm{mg}$ dose $(P=0.069)$. MCCB was administered to US patients only. Mean baseline values were 29.0, 26.6, and 31.0 for encenicline 0.27 and $0.9 \mathrm{mg}$ groups and placebo. (b) Overall Cognition Index (OCl): the primary efficacy end point of the study showing change in response from baseline. Significant effects were noted in the encenicline $0.27 \mathrm{mg}$ group $(P=0.034)$, but not in the $0.9 \mathrm{mg}$ group. Mean baseline values were $-0.05,-0.02$, and 0.02 for encenicline 0.27 and $0.9 \mathrm{mg}$ groups and placebo. (c) The post hoc analysis of the PANSS cognitive impairment domain showing dose-dependent pro-cognitive effects with encenicline reaching statistical significance at the $0.9 \mathrm{mg}$ dose $(P=0.0098)$. Baseline values were 19.7, 20.6, and 19.8 for encenicline 0.27 and $0.9 \mathrm{mg}$ groups and placebo.

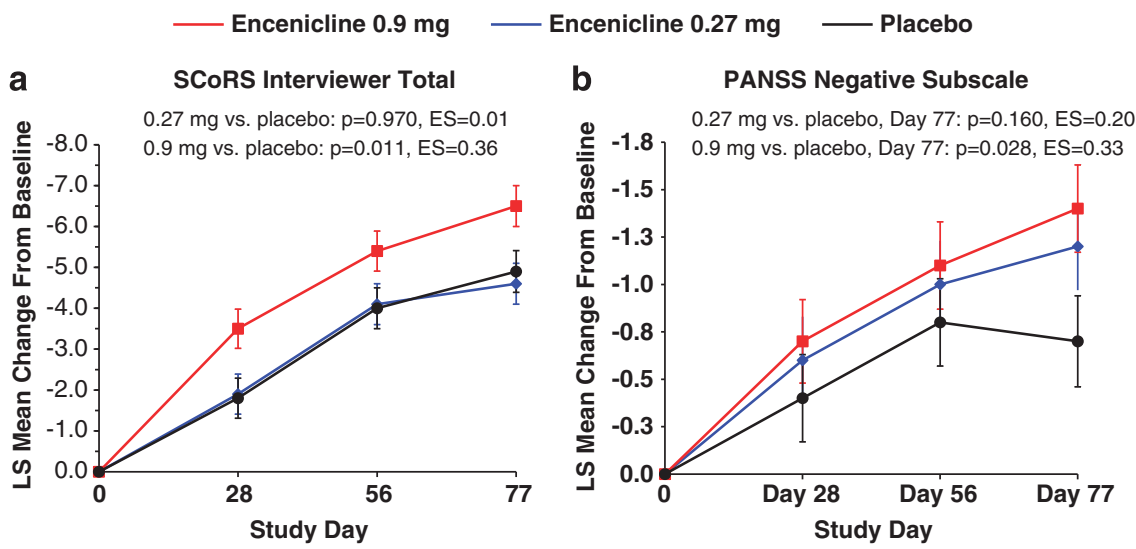

Figure 3 Composite figure of secondary outcomes. All data presented as mean \pm SEM. ES = Cohen's $d$ effect size. (a) SCoRS Interviewer total score evaluating changes in patient functioning from baseline. Statistically significant changes noted in the encenicline $0.9 \mathrm{mg}$ dose $(P=0.0 \mathrm{II}, \mathrm{ES}=0.36)$. Mean baseline values were 37.2, 38.5, and 37.3 in the encenicline 0.27 and $0.9 \mathrm{mg}$ groups and in the placebo group. (b) PANSS Negative Subscale demonstrating dose-dependent change from baseline reaching significance at the encenicline $0.9 \mathrm{mg}$ dose $(P=0.028, E S=0.33)$. Mean baseline values were I7.9, I8.7, and 19.0 in the encenicline 0.27 and $0.9 \mathrm{mg}$ groups and the placebo group.

\section{Safety and Tolerability}

In general, the adverse event rates were consistent across all treatment groups (Table 2) with the highest rate (39\%) of TEAEs observed in the placebo group. Headache was the most common TEAE experienced by encenicline-treated patients $(4.7 \%$ in the $0.27 \mathrm{mg}$ group and $4.8 \%$ in the $0.9 \mathrm{mg}$ group $v s 1.9 \%$ in the placebo group).

Other TEAEs experienced by $\geq 2$ patients in any encenicline group and with at least twice the incidence of placebo included nasopharyngitis (3.8\% vs $1.9 \%$, placebo), rash $(2.9 \% v s$ no patient in the placebo group), and dizziness (2.9\% vs $1.0 \%$, placebo). Six serious adverse events occurred in six patients; exacerbation of schizophrenia with encenicline $0.27 \mathrm{mg}$, exacerbation of schizophrenia and schizoaffective disorder, and pharyngitis, with encenicline $0.9 \mathrm{mg}$, and depression and lower limb fracture with placebo. No serious adverse events were considered related to study medication. No clinically important changes in vital signs, laboratory results, or ECG parameters were observed in any treatment group, and no event related to these parameters was considered severe or serious.

In total, TEAEs were the cause for early study discontinuation in 12 patients: 2 patients with encenicline $0.27 \mathrm{mg}$, 5 patients with encenicline $0.9 \mathrm{mg}$, and 5 patients with placebo. 
Table 2 Incidence of Treatment-Emergent Adverse Events (TEAEs) Occurring in at Least Two Patients in Any Treatment Arm

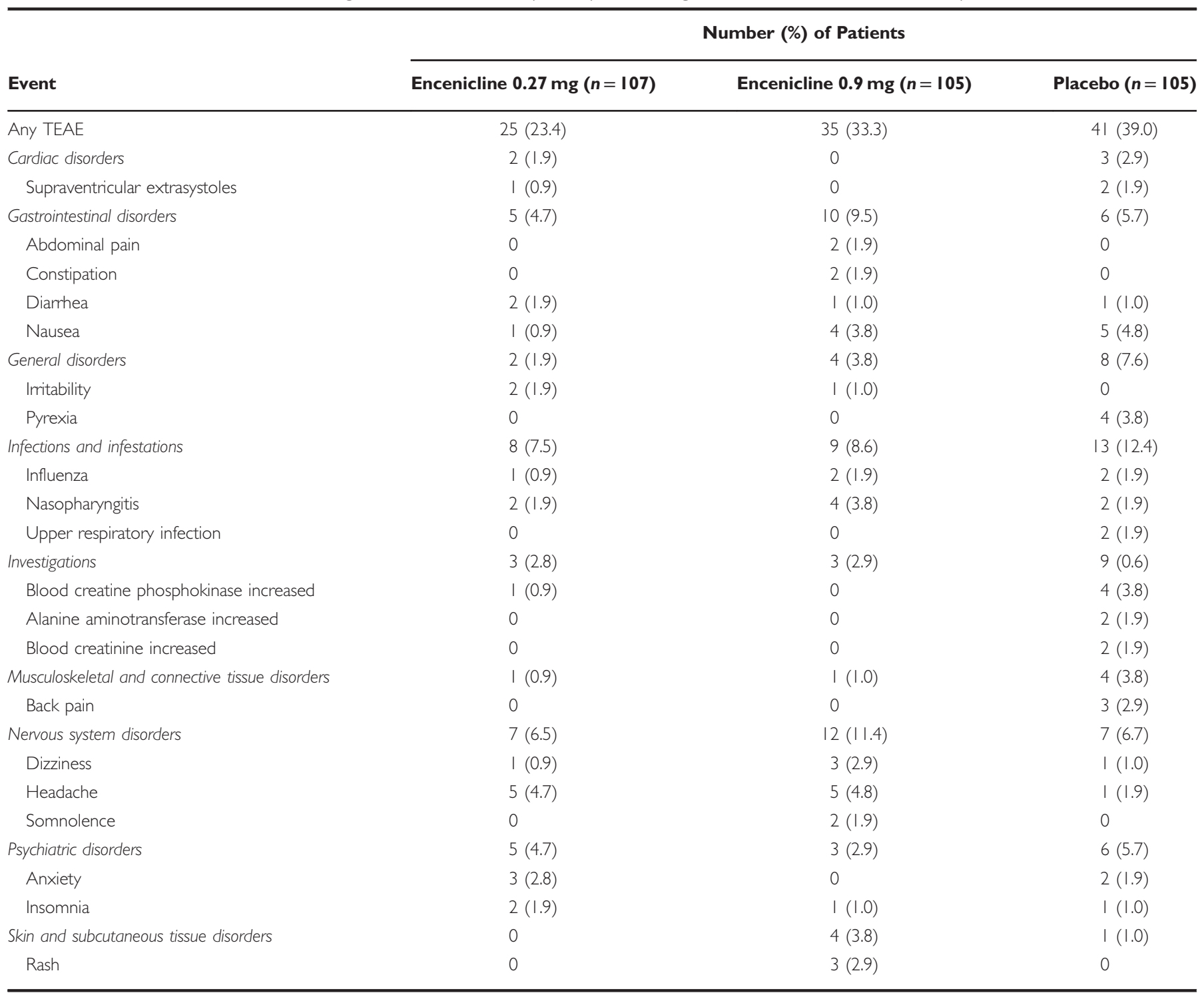

The occurrence and severity of EPS-related events (eg, tremor, akathisia, and extrapyramidal disorder) and EPS symptoms were evaluated by the SAS. Four patients experienced an EPS-related TEAE, including two patients in the encenicline $0.9 \mathrm{mg}$ group (tremor and extrapyramidal disorder) and two patients in the placebo group (tremor and akathisia). All EPS-related events were of mild severity, and no event was serious or required concomitant anti-EPS medications. No significant weight gain was noted in any of the treatment arms.

\section{DISCUSSION}

In this phase 2 study, encenicline, an $\alpha 7$ receptor agonist, was assessed in patients with schizophrenia and schizoaffective disorder stabilized on concomitant atypical antipsychotics. Multiple measures of cognition were built into this study that was designed to assess and characterize the potential effects of encenicline on enhancing cognition, function, and negative symptoms, as well as to further understand the safety profile of the drug.

This study demonstrated consistent beneficial effects of encenicline across multiple measures of cognition and function, with the most consistent effects apparent in the encenicline $0.9 \mathrm{mg}$ group. For the primary end point, the CogState OCI plus trails 2 and 4, encenicline was statistically superior to placebo at the $0.27 \mathrm{mg}$ dose, but not for the $0.9 \mathrm{mg}$ dose. In other measures of cognition, the MCCB and the PANSS Cognition Impairment Domain, improvement trends were noted with both encenicline doses, with a numerically greater effect seen in the $0.9 \mathrm{mg}$ dose. For the functional capacity outcome, statistically significant effects with encenicline $0.9 \mathrm{mg}$ were noted on the SCoRS total score. Moreover, statistically significant improvements in negative symptoms on the PANSS Negative Subscale were noted in the encenicline $0.9 \mathrm{mg}$ group. Both of these measures showed effects consistent with the MCCB and PANSS measures of cognition. 
Interestingly, a higher than expected and more variable placebo response was seen with the CogState OCI, whereas a more typically anticipated response of the placebo group was seen for both the MCCB and the PANSS Cognitive Impairment Domain. Although the reasons for the computerized CogState battery to produce placebo results notably different from both the MCCB and PANSS are unclear, it is perhaps due to these findings that the overall results of the CogState were inconsistent with the other measures of cognition and cognitive function in this study. The disparate dose-response results on the CogState $v s$ the MCCB may indicate that the MCCB is a 'better' measure of cognition as it correlates more closely with clinical benefit (dose-response correlation with the SCoRS and PANSS Neg) and the PANSS Cognition Factor analysis or may be due to variability. This will require further study.

The MCCB, PANSS Cognition analysis, and the SCoRS all showed notable, dose-dependent, and consistent improvement with the $0.9 \mathrm{mg}$ dose of encenicline compared with placebo, and placebo responses that were more in keeping with the general literature. The effect of the $0.9 \mathrm{mg}$ dose of encenicline as measured by MCCB was noted as a trend $(P=0.069)$ despite the fact that these assessments were collected for only about half of the study sample (154/317), due to unavailable validated MCCB translations outside of the United States. The PANSS Cognition and SCoRS ratings were collected and analyzed for the entire study population, and both showed statistical significance for the $0.9 \mathrm{mg}$ group as compared with placebo. Both 0.27 and $0.9 \mathrm{mg}$ encenicline doses were generally well tolerated. No serious safety signals were identified for encenicline-treated patients compared with placebo, and the overall safety profile was consistent with the known pharmacology of encenicline.

Taken together, the encouraging effects on cognition in addition to a generally well-tolerated safety profile warrant further studies with larger populations, longer durations, and a higher dose to further elucidate the potential cognitive enhancing effects of encenicline in stable schizophrenic patients.

\section{FUNDING AND DISCLOSURE}

ND, HJM, MG, IL, GK, and DCH were employees for FORUM Pharmaceuticals when this study was conducted. IL is an employee of and receives salary from Axovant Sciences. HAM is a consultant to Alkermes, Astellas, Boehringer Ingelheim, Auspex, Naurex, Novartis, and ProPhase; receives grant/ research support from Dainippon Sumitomo, Forum Pharmaceuticals, Naurex, Astellas, Otsuka Reviva, Suregene, and Sunovion; has received honoraria from Dainippon Sumitomo, Forum Pharmaceuticals, Naurex, Astellas, Ostuka, Reviva, Suregene, and Sunovion; has served on speakers or advisory boards for Sunovion, Novartis, Reviva, ProPhase, Auspex, and Forum Pharmaceuticals; and is a stockholder in SureGene and AstraZeneca. RSEK has currently or in the past 3 years received investigator-initiated research funding support from the Department of Veteran's Affair, Feinstein Institute for Medical Research, GlaxoSmithKline, National Institute of Mental Health, Novartis, Psychogenics, Research Foundation for Mental Hygiene, and the Singapore National Medical Research Council. He has currently or in the past
3 years received honoraria, served as a consultant, or advisory board member for Abbvie, Akebia, Amgen, Asubio, AviNeuro/ ChemRar, BiolineRx, Biogen Idec, Biomarin, BoehringerIngelheim, Eli Lilly, EnVivo, GW Pharmaceuticals, Lundbeck, Merck, Minerva Neurosciences, Mitsubishi, Novartis, NY State Office of Mental Health, Otsuka, Pfizer, Reviva, Roche, Sanofi/Aventis, Shire, Sunovion, Takeda, Targacept, and the University of Texas South West Medical Center. RSEK receives royalties from the BACS testing battery, the MATRICS Battery (BACS Symbol Coding), and the Virtual Reality Functional Capacity Assessment Tool (VRFCAT). He is also a shareholder in NeuroCog Trials and Sengenix.

\section{ACKNOWLEDGMENTS}

We acknowledge the editorial assistance of Richard S Perry in the preparation of this manuscript that was supported by FORUM Pharmaceuticals, Waltham, MA. Michael Stevenson and Andrew Hsieh, both of FORUM Pharmaceuticals, provided editorial assistance and data confirmation.

\section{AUTHOR CONTRIBUTIONS}

RSEK, ND, HJM, MG, and DCH were involved in the design, data collection, analysis, and interpretation of the study. $\mathrm{HJM}$ and GK were involved in data interpretation? IL was involved in analysis and interpretation of the study. All authors were involved in the decision to submit the manuscript for publication.

\section{REFERENCES}

Addington D, Addington J, Schissel B (1990). A depression rating scale for schizophrenics. Schizophr Res 3: 247-251.

Barbier AJ, Hilhorst J, van Vliet A, Snyder P, Palfreyman MG, Gawryl M et al (2015). Pharmacodynamics, pharmacokinetics, safety, and tolerability of encenicline, a selective $\alpha_{7}$ nicotinic receptor partial agonist, in single ascending dose and bioavailability studies. Clin Ther 37: 311-324.

Barik J, Wonnacott S (2009). Molecular and cellular mechanisms of action of nicotine in the CNS. Handb Exp Pharmacol 192: 173-207.

Bilder RM, Goldman RS, Robinson D, Reiter G, Bell L, Bates JA et al (2000). Neuropsychology of first-episode schizophrenia: initial characterization and clinical correlates. Am J Psychiatry 157: 549-559.

Cohen J (1977). Statistical Power Analysis for the Behavioral Sciences, 2nd edn. Lawrence Erlbaum Associates: Mahwah, NJ.

Green MF, Nuechterlein KH, Gold JM, Barch DM, Cohen J, Essock S et al (2004). Approaching a consensus cognitive battery for clinical trials in schizophrenia: the NIMH-MATRICS conference to select cognitive domains and test criteria. Biol Psychiatry 56: 301-307.

Harvey PD, Keefe RS (1997). Cognitive impairment schizophrenia and implications of atypical neuroleptic treatment. CNS Spectrums 2: $1-11$.

Harvey PD, Sukhodolsky D, Parrella, White L, Davidson M (1997). The association between adaptive and cognitive deficits in geriatric chronic schizophrenic patients. Schizophr Res 27: 211-218.

Heinrichs RW, Zakzanis K (1998). Neurocognitive deficits in schizophrenia: a quantitative review of the evidence. Neuropsychology 12: 426-445.

Huang M, Felix AR, Flood DG, Bhuvaneswaran C, Hilt D, Koenig G et al (2014). The novel $\alpha 7$ nicotinic acetylcholine receptor agonist 
EVP-6124 enhances dopamine, acetylcholine, and glutamate efflux in rat cortex and nucleus accumbens. Psychopharmacology (Berl) 231: 4541-4551.

Kay SR, Fiszbein A, Opler LA (1987). The positive and negative syndrome scale (PANSS) for schizophrenia. Schizophr Bull 13: 261-276.

Keefe RS, Poe M, Walker TM, Kang JW, Harvey PD (2006). The Schizophrenia Cognition Rating Scale: an interview-based assessment and its relationship to cognition, real world functioning, and functional capacity. Am J Psychiatry 163: 426-432.

Keefe RSE, Fox KH, Harvey PD, Cucchiaro J, Siu C, Loebel A (2011). Characteristics of the MATRICS consensus cognitive battery in a 29 site antipsychotic schizophrenia clinical trial. Schizophr Res 125: 161-168.

Keefe RS, Davis VG, Spagnola NB, Hilt D, Dgetluck N, Ruse S et al (2015). Reliability, validity and treatment sensitivity of the Schizophrenia Cognition Rating Scale. Eur Neuropsychopharmacol 25: 176-184.

Kern RS, Nuechterlein KH, Green MF, Baade LE, Fenton WS, Gold JM et al (2008). The MATRICS consensus cognitive battery: part 2. Co-norming and standardization. Am J Psychiatry 165: 214-220.

Maruff P, Thomas E, Cysique L, Brew B, Collie A, Snyder P et al (2009). Validity of the CogState brief battery: relationship to standardized tests and sensitivity to cognitive impairment in mild traumatic brain injury, schizophrenia, and AIDS dementia complex. Arch Clin Neuropsychol 24: 165-178.

Mohamed S, Rosenheck R, Swartz M, Stroup S, Lieberman JA, Keefe RSE (2008). Relationship of cognition and psychopathology to function impairment in schizophrenia. Am J Psychiatry 165: 978-987.

Mohs PE, Cheng CM, Claxton K, Conley RR, Feldman JJ, Hargreaves WA et al (2004). The heterogeneity of schizophrenia in disease states. Schizophr Res 71: 83-95.

Nuechterlein KH, Green MF, Kern RS, Baade LE, Barch DM, Cohen JD et al (2008). The MATRICS Consensus Cognitive Battery, part 1: test selection, reliability, and validity. Am J Psychiatry 165: 203-213.

Overall JE, Gorham DR (1962). The brief psychiatric rating scale. Psychol Rep 10: 799-812.

Picciotto MR, Zoli M, Rimondini R, Lena C, Marubio LM, Pich EM et al (1998). Acetylcholine receptors containing the beta2 subunit are involved in the reinforcing properties of nicotine. Nature 391: 173-177.

Pichat P, Bergis OE, Terranova J-P, Urani A, Duarte C, Santucci V et al (2007). SSR180711, a novel selective alpha7 nicotinic receptor partial agonist: (II) efficacy in experimental models predictive of activity against cognitive symptoms of schizophrenia. Neuropsychopharmacology 32: 17-34.

Posner K, Oquendo MA, Gould M, Stanley B, Davies M (2007). Columbia classification algorithm of suicide assessment (CCASA). Am J Psychiatry 164: 1035-1043.

Preskorn SH, Gawryl M, Dgetluck N, Palfreyman M, Bauer LO, Hilt DC (2014). Normalizing effects of EVP-6124, an alpha-7 nicotinic partial agonist, on event-related potentials and cognition: a proof of concept, randomized trial in patients with schizophrenia. J Psychiatr Pract 20: 12-24.

Prickaerts J, van Goethem NP, Chesworth R, Shapiro G, Boess FG, Methfessel C et al (2012). EVP-6124, a novel and selective $\alpha 7$ nicotinic acetylcholine receptor partial agonist, improves memory performance by potentiating the acetylcholine response of a7 nicotinic acetylcholine receptors. Neuropharmacology 62: 1099-1110.

Saykin AJ, Gur RC, Gur RE, Mozley PD, Mozley LH, Resnick SM et al (1991). Neuropsychological function in schizophrenia. Selective impairment in memory and learning. Arch Gen Psychiatry 48: 618-624.

Saykin AJ, Shtasel DL, Gur RE, Kester DB, Mozley LH, Stafiniak P et al (1994). Neuropsychological deficits in neuroleptic naïve patients with first-episode schizophrenia. Arch Gen Psychiatry 51: 124-131.

Simpson GM, Angus JWS (1970). A rating scale for extrapyramidal side effects. Acta Psych Scand 212: 11-19.

(c) (i) $(-)$ This work is licensed under a Creative Commons cc) Attribution-NonCommercial-NoDerivs 4.0 International License. The images or other third party material in this article are included in the article's Creative Commons license, unless indicated otherwise in the credit line; if the material is not included under the Creative Commons license, users will need to obtain permission from the license holder to reproduce the material. To view a copy of this license, visit http://creativecommons.org/licenses/by-nc-nd/4.0/

Supplementary Information accompanies the paper on the Neuropsychopharmacology website (http://www.nature.com/npp) 